\title{
The influence of Biodanza and School of Empathy verbal - respectful communication on the ability to express emotions and needs: a pilot study among adults in Indonesia
}

\begin{abstract}
BACKGROUND
Cultural aspects play a dominant role in a certain country related to emotional expressions, particularly in Indonesia. Biodanza and School of Empathy have been developing and are recognized as an alternative psychological intervention in fostering the ability to express feelings, generate positive emotions and alleviate negative one. The aim of this study is to explore the implementation of Biodanza (nonverbal part) and School of Empathy (SoE) verbal part in expressing emotions and needs among adults in Indonesia.

PARTICIPANTS AND PROCEDURE

This study in Indonesia consisted of 2 groups. Group 1 was conducted through Biodanza with 17 participants and group 2 was the SoE verbal part with 17 participants $(N=34)$. All participants in both studies were collected randomly through online advertisements. We administered both closed and open-ended questionnaires to ascertain the current feeling as well as the ability to express emotions and needs before and after the interventions in groups 1 and 2 .
\end{abstract}

\section{RESULTS}

We found different themes between group 1 and group 2 . Participants who received the Biodanza showed a signifi- cantly increasing score of ability to express emotions, while the ability to express needs is not increased significantly. Furthermore, SoE indicated no significant difference in their ability to express their emotions and needs between the pre-test and post-test score.

\section{CONCLUSIONS}

For the samples of the Indonesian population in implementing Biodanza and SoE verbal part, the cultural aspect plays a very significant role in discussing these findings. Overall, the findings of this study suggest that Biodanza has the potential to be a practical approach to assisting individuals in deriving positive benefits for their emotional well-being. The evaluation of SoE verbal part should be made related to the material, due to cultural barrier findings. Future research is expected to fuse various measurements that were not included in this study.

\section{KEY WORDS}

Biodanza; School of Empathy verbal; Indonesia; needs expression; emotion expression

ORGANIZATION - 1: DPFA Academy of Work and Health, Leipzig, Germany · 2: International Research Academy - BIONET, Leipzig, Germany · 3: Family Empowerment Center, Faculty of Psychology, Diponegoro University, Semarang, Indonesia - 4: Center of Child and Family Studies, Department of Psychology, Islamic University of Indonesia, Yogyakarta, Indonesia

AUthors' Contributions - A: Study design - B: Data collection - C: Statistical analysis - D: Data interpretation . E: Manuscript preparation · F: Literature search · G: Funds collection

Corresponding Author - Dian Sari Utami, Ph.D., Center of Child and Family Studies, Department of Psychology, Islamic University of Indonesia, Yogyakarta, Indonesia, e-mail: dian.utami@uii.ac.id

to Cite this ARticle - Stueck, M., Sakti Kaloeti, D. V., Villegas, A., \& Utami, D. S. (2019). The influence of Biodanza and School of Empathy verbal - respectful communication on the ability to express emotions and needs: a pilot study among adults in Indonesia. Health Psychology Report, 7(4), 334-340. https://doi.org/10.5114/hpr.2019.88665 


\section{BACKGROUND}

Biodanza is an autoregulative method from South America, developed by Rolando Toro. It works with dances and experiences in five lines: Creativity, Vitality, Affectivity, Transcendence, and Sexuality. Biodanza has been spreading since the 1960s all over the world. Biodanza is done in most countries. There are regions where it is a challenge to introduce Biodanza, because of political, religious, cultural reasons, e.g., Indonesia. As an archipelago, Indonesia is the third biggest country in the world, with 17,500 islands and more than 250 languages. According to Hofstede (2007, 2011), Indonesia has a low individualism score and high score in power distance. Therefore, as a collective culture, it represents a particular challenge to work particularly with Biodanza, which focuses on the nonverbal aspect, especially in the theme of identity development and expression of emotions. First of all, it needs to build up trust by using the research about Biodanza.

If humans cannot express their feelings, they have a potential for getting insight tension (sympathetic activation) or deactivation (parasympathetic stimulation), because underneath the feelings are hidden needs, which cannot be expressed and realized as well. This suppression (see Figure 1), in the end, can lead to psychosomatic illness (Alexander, 1950; Stueck, 2007; Adler et al., 2003).

That is why it makes sense to develop psychological methods for expressing emotions and feelings, e.g., by using art, music, dance, language, poetry. As research has shown (Stueck \& Villegas, 2008) the specific effect of Biodanza is the extensive range of emotional expressions after the session in comparison to other emotion regulative methods, e.g., yoga (see Table 1).

In 2010, we introduced Biodanza in the framework of the Concept "School of Empathy" (SoE), developed by Stueck in Germany from a Ministry of Health Project 2007-2011 as a framework concept of our work at the Islamic University of Indonesia in Yogyakarta. SoE (Stueck, 2013) consists of two intervention strategies:

1. Verbal (language-based) methods to increase empathy, e.g., respectful communication, based on Marshal Rosenberg (2015); deep democracy, based on the works of Mindell (2002), theatre-based interventions and exercises and cognitive naturalbased reflections (e.g., presentations studies about empathic links in animals, plants). It is away from the body in the head with a connecting language, which means from the feeling based communication to the rational verbal (e.g., expression of feel-
The influence of Biodanza and School of Empathy verbal

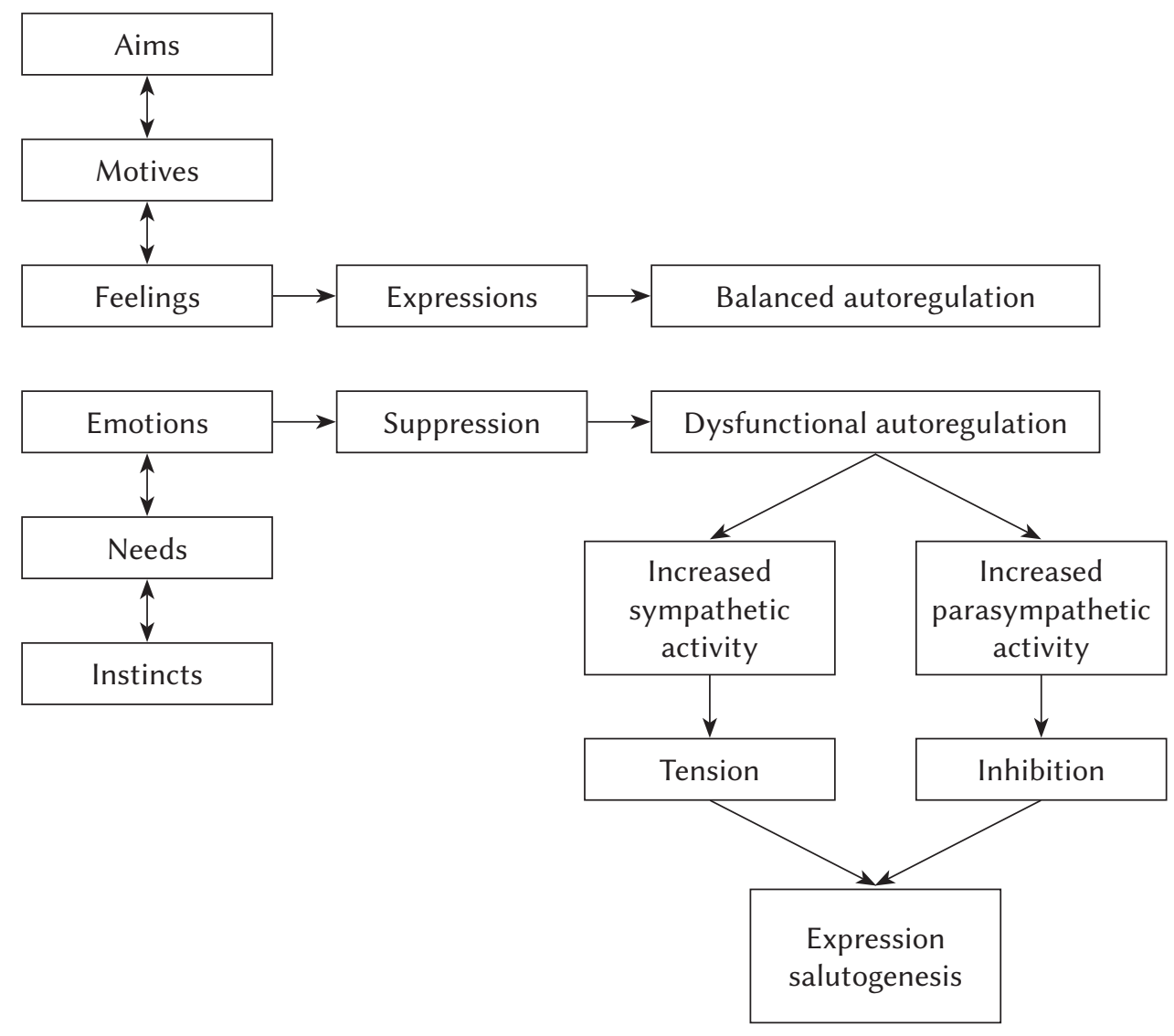

Figure 1. Basic model about the main aspects of human behavioural organization, salutogenesis and emotional expression (Stueck, 2007). 
Table 1

Comparison of emotional expression between Biodanza and yoga

\begin{tabular}{lcc}
\hline$N=50$ & $\begin{array}{c}\text { Biodanza } \\
\text { After class } \\
\text { (in \%) a }\end{array}$ & $\begin{array}{c}\text { Yoga } \\
\text { After class } \\
\text { (in \%) }\end{array}$ \\
\hline $\begin{array}{l}\text { Positive } \\
\text { emotional states }\end{array}$ & $58.80(73.70)$ & $19.50(65.40)$ \\
$\begin{array}{l}\text { Negative } \\
\text { emotional states }\end{array}$ & $21.00(26.30)$ & $10.30(34.60)$ \\
$\Sigma$ Sum & $79.80(100.00)$ & $29.80(100.00)$ \\
\hline
\end{tabular}

ings, needs, observation language, and integrative language to include all voices).

2. Nonverbal (body-oriented) methods to increase empathy, e.g., Biodanza, art therapy, yoga, chi gong, meditation, praying. It is away from the head to the heart and body, which means from the rational verbal to the feeling based communication, working with the experience (Spanish: Vivencia).

These two pathways can be trained by evidencebased training:

1. SoE (verbal part): Training of respectful communication, developed in Germany by Mueller and Poerschmann (2009) in 2 versions (10 sessions) for 4-6 year and 7-12 year old children and evaluated in several research works (Schoppe \& Stueck, 2012).

2. Biodanza (nonverbal part): Biodanza-training for kindergarten (3-6 years) and school children developed by Marcus Stueck, Alejandra Villegas, Vineta Greaves, and Andrea Schult in 2010 on the basis of the Biodanza work of Cecilia Luzzi in children. Several studies have evaluated this TANZPRO-Biodanza for children programme (Stueck et al., 2016).

In a second step, we did studies with these two intervention strategies in Indonesia, to test the effects in another culture. For this, we had to train trainers from 2009 to 2013 at the UII (Universitas Islam Indonesia/Islamic University of Indonesia) and in a private course in Jakarta with 60 participants. Some of these course instructors used six sessions of Biodanza and four sessions of SoE verbal - Respectful Communication to work with children in schools.

The first study of SoE among children in Indonesia was conducted by Trimulyaningsih, Novitasari, and Qudsyi (2014), who found that it is necessary to adapt the concept of SoE non-violent communication (NVC) based on culture. The formulation of consideration about NVC implementation in Indonesia is related to 1) appropriateness with the stages of child development, 2) application of NVC in a various culture, and 3) appropriateness with the religious belief in Indonesia. Further is the second study of the developing module of NVC in the Indonesia context (Qudsyi,
Trimulyaningsih, Novitasari, \& Stueck, 2018). Based on the result of the study, the evaluations were performed related to training procedure, description of activities in one section of training, instruction of activities in one section of training, topics of the story on activities in one section of training, and sentences used in training instructions. Most participants responded with "happy" emotions while doing the activities. Some children can discuss their basic emotions (i.e., joy, sadness, anger). However, for higher emotion levels of self-consciousness emotions (i.e., proud, shy, moved) are not visible during the session. It was also found that there was a lack of understanding of emotional vocabulary among participants.

Among those previous studies of SoE NVC, the Indonesian researchers investigated the effect of SoE on children's well-being (Widiasmara, Novitasari, Trimulyaningsih, \& Stueck, 2018). It was found that there were no differences in children's well-being between control and experiment groups. However, the SoE training has a moderate effect towards a positive outlook rather than a positive emotional state among children.

Therefore, in the current study, we aim to explore the role of both the Biodanza (nonverbal part) and SoE (verbal part) in fostering the ability to express emotions and needs among adults in Indonesia. We hypothesized that there is a difference in expressing emotions and needs among adults in Indonesia before and after the Biodanza and the SoE verbal part.

\section{PARTICIPANTS AND PROCEDURE}

\section{PARTICIPANTS}

We conducted our field research on Java Island, the biggest population in Indonesia. This study consists of two groups. In group 1, a total of 17 participants were investigated before and after Biodanza. In group 2, a total of 17 participants participated in SoE verbal part. Participants were teachers, educators, students, and parents from Yogyakarta and Central Java Province. The Biodanza session was conducted in 2019 in a public university in Semarang city and SoE verbal part in a private university in Yogyakarta city.

Participants of this study were collected randomly and voluntarily through online advertisements in Central Java and Yogyakarta. They were informed that they would follow the Biodanza programme (in Semarang) and SoE verbal programme (in Yogyakarta). They had to be at least 18 years old and Indonesian. Exclusion criteria included psychiatric illness and serious physical disability. Participants completed baseline questionnaires before the session (pretest) and after the session (post-test). Participants in group 1 and group 2 were different. After completing the initial pre-test, they commenced the programme. 


\section{MATERIALS AND PROCEDURE}

Procedure of group 1. The Biodanza intervention was led by the same, experienced and highly trained trainer. The session lasted 90 minutes. In the beginning, participants were encouraged to talk about themselves. Afterwards, they had a warm-up period with music and low-intensity movements in the welcome circle. During the next 40 minutes they performed more active movements, including walking, dancing, exercising and finishing up with a 10-minute final celebration round. In the end, participants were asked to share their feeling or emotions. The movements were based on natural human movements, such as walking and shaking hands. The archetypical gestures come from the original gestures of human expression belonging to different cultures, such as bowing (López-Rodríguez et al., 2017).

Procedure of group 2. The first step of the course was conducted by giving the pre-questionnaire to each participant. Second, an opening session was done by the trainer by asking participants feelings and in which situation the feeling occurred. Third, all participants were in a group and stimulated by music while walking around the room. When the music stopped playing, participants communicated about each other's feelings in pairs and described which situations precipitated the feeling. Fourth, the trainer gave a theoretical background of SoE verbal respectful communication which consists of 5 sessions based on Rosenberg (2007) and Mueller and Poerschmann (2009): 1) introduction, 2) observation, 3) knowing emotion, 4) understanding needs, and 5) making requests. At each session, the trainer explained and let the participants perform exercises in pairs or groups and opened discussions in the sessions. Fifth, all par-

Table 2

Open-ended questionnaire

No. Item

1. How easy is it to express your feelings?

2. How easy is it to express your needs?

3. What kind of feelings do you point out frequently?

4. What kind of needs do you express frequently?

5. How much do you intend to Open-ended join this programme?

6. What is the lesson that you want to get from this programme?

Close-ended
Close-ended
Open-ended
Open-ended
Open-ended

ticipants were asked to fill out the post-questionnaire after the last session.

This study used both open- and close-ended questionnaires. The close-ended questionnaire consists of two questions with the score range 1-10 reflecting the lowest to the highest level of perceived ability to express feelings and needs. The open-ended questionnaire consists of six questions (Table 2). The questions are about further exploration about their kinds of most showed feelings and needs as well as programme evaluation.

Pre-test and post-test measures were compared between groups using the Mann-Whitney $U$ test (close-ended question) as well as descriptive analysis (open-ended question) to sharpen the analysis. Within-group comparisons were carried out to explore the effects of the programme in each group, as per the study objectives. The between-group analysis was used to compare these changes with those observed in the control group. A $p$-value of $<.05$ was considered significant in all tests.

\section{RESULTS}

\section{DESCRIPTIVE ANALYSIS}

Descriptive analysis was conducted between group 1 and group 2 separately before the session of Biodanza and SoE verbal part. We described some themes in both groups related to positive and negative feelings and needs of participants. However, we found the different themes for each group related to the most showed feelings and needs.

Group 1:

Qualitative results revealed that participants had an overall positive perception of the Biodanza in the form of a feeling of stable, fluctuating, sad and anxious, happy and excited after doing a Biodanza session (Figure 2). They expressed willingness to prac-

The influence of Biodanza and School of Empathy verbal

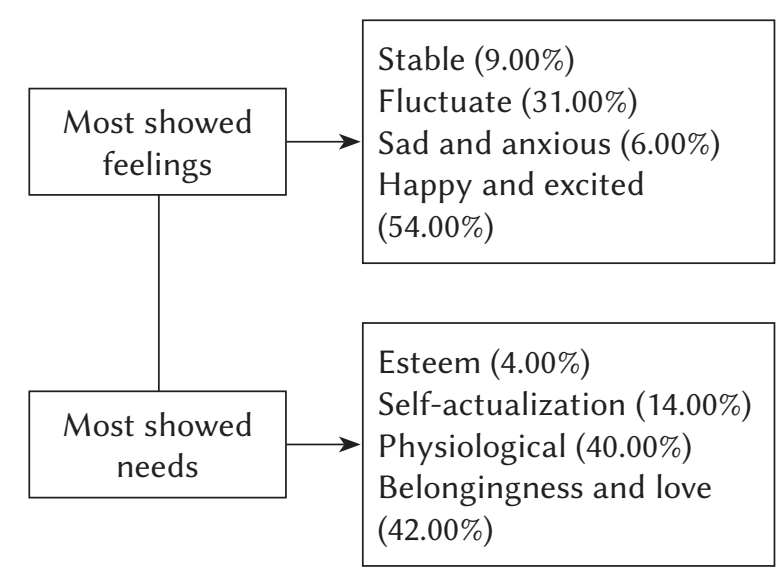

Figure 2. Descriptive analysis of Biodanza group. 
Marcus Stueck,

Dian Veronika Sakti Kaloeti, Alejandra Villegas, Dian Sari Utami

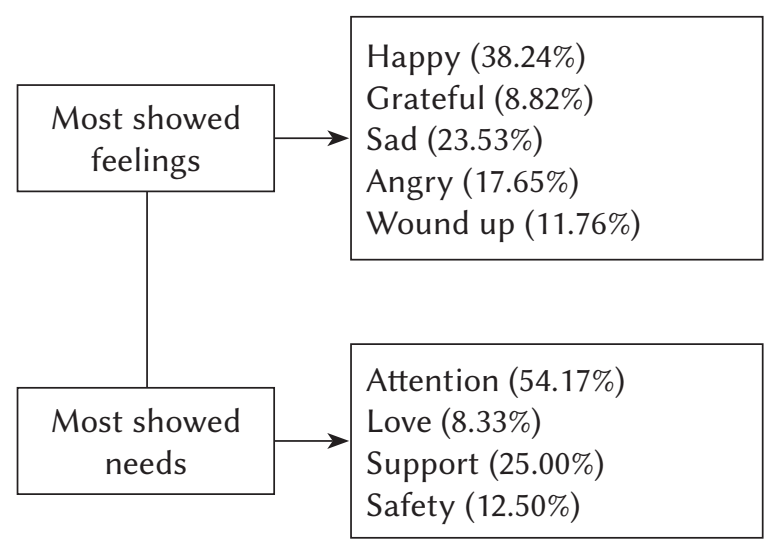

Figure 3. Descriptive analysis of SoE verbal part group.

tise and learn more about Biodanza so that they can implement this method to their family, partner, clients, and students.

Group 2:

As depicted in Figure 3 above, the SoE verbal group reported positive feelings, e.g. most of them were feeling happy and fewer reported grateful and negative feelings (i.e., sad, angry and wound up). Also, they showed some needs related to attention, support, safety, and love.

\section{BETWEEN-GROUP ANALYSIS}

Measurements of emotions and needs expression of 17 participants in each group after completing the Biodanza session in Semarang (group 1) and SoE -

A

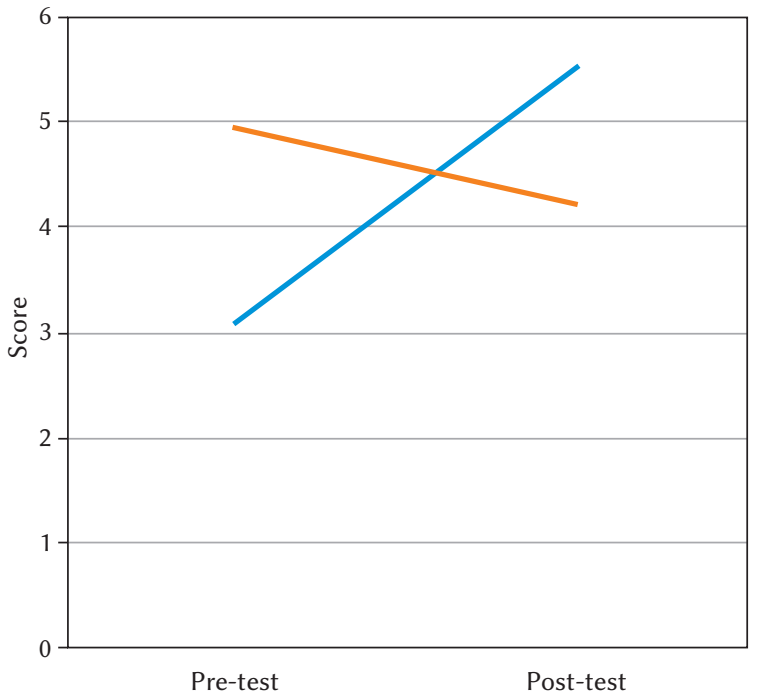

verbal part (group 2) in Yogyakarta were calculated using the Mann-Whitney Utest. For Biodanza participants, they showed significant results for subjects expressing emotions $\left(M_{\text {pretest }}=3.12 \pm 1.90, M_{\text {posttest }}=5.53\right.$ $\pm 1.46, Z=-3.43, p<.001)$. Different results were obtained for SoE-verbal participants, who showed no significant differences in terms of ability to express emotions $\left(M_{\text {pretest }}=4.94 \pm 1.60, M_{\text {posttest }}=4.24 \pm 1.85\right.$, $Z=-1.40, p>.05)$. On the other hand, the Biodanza session was not able to increase their ability to express their needs $\left(M_{\text {pretest }}=3.59 \pm 1.69, M_{\text {posttest }}=3.59 \pm 1.87\right.$, $Z=0.00, p>.05)$ as well as the SoE-verbal participants $\left(M_{\text {pretest }}=5.65 \pm 1.32, M_{\text {posttest }}=4.59 \pm 1.94, Z=-1.75\right.$, $p>.05$ ).

Regarding the most frequently indicated needs, as many as $35.00 \%$ of Biodanza participants still have problems in meeting physiological needs and have problems with fulfilling psychological needs. On the other hand, participants of the SoE verbal part showed mostly the needs of attention $(54.17 \%)$ and support $(25.00 \%)$. This indicated that they still have problems with fulfilling those needs in daily lives.

The post-test results of Biodanza and SoE-verbal (see Figure 4) showed a significant difference in the ability to express emotions $(Z=-2.18, p<.05)$, but it was not significant for specific ability $(Z=-1.38$, $p>.05$ ). The post-test results of group 1 (Biodanza) and group 2 (SoE-verbal) showed a significant difference in the ability to express emotions $(t=2.39$, $p<.05)$, but it was not significant for expressing ability $(t=-1.43, p>.05)$.

In terms of emotional states, in the Biodanza group before the session, participants reported $58.82 \%$ positive emotional states like happiness, joy

B

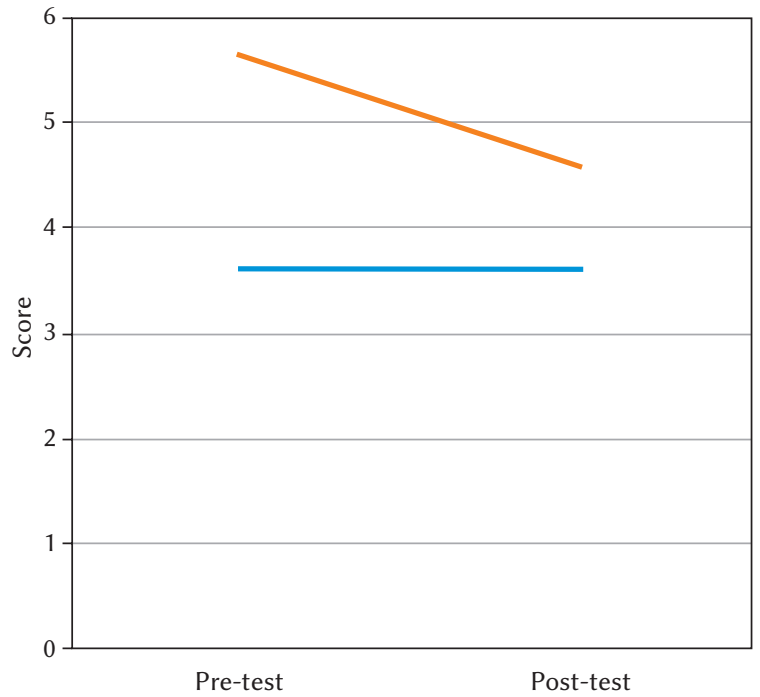

$$
\text { - Biodanza }- \text { SoE }
$$

Figure 4. Pre-test and post-test score for emotional expression (A) and need expression (B). 
and excitement and the rest reported a feeling of negative emotional states, such as worried and sad (see Table 3). After the class, almost all participants (94.12\%) reported a feeling of positive emotional states like very happy, relaxed and joyful. However, in the SoE verbal group before the session, participants reported $76.47 \%$ having positive feelings in their daily lives, such as happiness, joy, excitement, optimism and grateful. The rest of the participants (23.53\%) reported some negative emotional states like sad, angry, upset, and worried in their daily lives. After the session, all participants reported the feeling of positive emotional states, such as grateful, happy, and satisfied (see Table 3).

Qualitative results revealed that participants expressed willingness to practise and learn more about Biodanza and SoE-verbal so that they can implement this method to their family, partner, clients, and students.

\section{DISCUSSION}

The ability to express feelings and needs in this study is essential to consider the socio-cultural context. Both people in group 1 and 2 were internalized by Java culture. It is significant for Javanese to maintain relations with others in the entire amicable state. Cultural congruity is characterized by presentations of balance, arrangement, common help and thriving (Ip, 2014). A condition of harmony will happen if all composing parties are in a state of harmony, collaboration, and recognition in a calm and tolerant condition (Magnis-Suseno, 2003). Living in harmony in Indonesia is also one of the five basic life factors which are implemented as the country values. Individuals need to carefully see if they need to have potential conflict with others or have caused animosity. By having this consideration, individuals maintain compatibility, and tolerance in differing interests. Hence, the SoEverbal group members still face difficulties to fulfil their emotional expression and needs. Cultural barriers related to high power distance and masculinity in Indonesia (Hofstede, 2007) are assumed to make this occur. To maintain harmony with society, they tend to suppress their emotions and needs. These findings are in line with the previous research of SoE-verbal among children (non-violent communication) in Yogyakarta, Indonesia (Trimulyaningsih, Novitasari, \& Qudsyi, 2014; Qudsyi et al., 2018; Widiasmara et al., 2018). Javanese children had difficulties to express their feelings because there are around 100 words about emotion in Javanese language. Also, those children rarely use and communicate their emotional feelings in daily lives, even within families.

Despite the difficulties of participants that we found related to fulfilling emotional expression and needs, SoE-verbal gives various changing of emotional
Table 3
Participants' emotional states

\begin{tabular}{lcc}
\hline Participants' emotional & \multicolumn{2}{c}{ Measurement } \\
\cline { 2 - 3 } states & $\begin{array}{c}\text { Before } \\
\text { class }(\%)\end{array}$ & $\begin{array}{c}\text { After } \\
\text { class }(\%)\end{array}$ \\
\hline Biodanza $(n=17)$ & & \\
$\quad$ Positive emotional states & 58.82 & 94.12 \\
$\quad$ Negative emotional states & 41.48 & 5.88 \\
$\begin{array}{l}\text { School of Empathy verbal } \\
\text { (SoE-verbal) }(n=17)\end{array}$ & & \\
$\quad$ Positive emotional states & 76.47 & 100.00 \\
$\quad$ Negative emotional states & 23.53 & 0.00 \\
\hline
\end{tabular}

The influence and School of Empathy verbal of Biodanza

states before and after the session, especially in positive emotional expression. Some participants who reported negative feelings before the session mentioned that they felt happy and satisfied after the session of SoE-verbal. The concept of respectful communication which was trained in the SoE-verbal could accommodate the needs of participants related to attention, support, love, and safety in relations to others. However, the needs of attention and support are still considerations in the intervention of SoE-verbal. Participants reported after the session of SoE-verbal that they could find some difficulties to apply this to inexpressive people, in constant communication, how to accept a negative response, to make the feeling neutral, to understand others' feelings, and to express negative feelings like anger which tend to be repressed in society. This is supported with the previous study among children in Indonesia indicating that SoE-verbal tends to change the positive outlook of individual emotions rather than feelings (Widiasmara et al., 2018). Compared with the SoE-verbal, Biodanza gives a promising approach to help people become aware of their emotion. In group 1, Biodanza is significant for improving emotional expression but not in their ability to express needs. Further, there was a strong significant correlation between the ability to express emotion and needs. Regarding the most frequently indicated needs fewer participants in Biodanza (group 1) have problems in meeting physiological needs and fulfilling psychological needs. In the Biodanza groups, social, love needs and physiological are the highest needs.

We addressed some limitations in our study for both groups. First, due to the limited time to recruit participants, the number of participants was not representative and most of the participants were psychology students who can be assumed to have more knowledge and experience related to this study. Further, we realize that the session for both groups should be longer to obtain more obvious change and give participants more time to apply and experience 
in their daily lives during the session. Thus, the cultural barriers could be observed and reported systematically and measured. The length of the programme will help us to evaluate it in case some adaptation of the content in Biodanza and SoE verbal part is needed.

\section{CONCLUSIONS}

Marcus Stueck,

Dian Veronika

Sakti Kaloeti, Alejandra Villegas, Dian Sari Utami

Overall, the findings of this study suggest that Biodanza and SoE verbal part have the potential to be practical approaches to assist individuals in deriving positive benefits for their emotional expression among adults in Indonesia. However, the SoE-verbal approach is necessary to facilitate individuals in their ability to express needs of attention and support in collective culture, such as Indonesia. Future research is expected to fuse various measurements comprehensively that were not included in this study, including physical wellness, psychological wellbeing and cognitive functioning. Proper participant number, long-term intervention, evaluation/adaptation of module, and follow-up are necessary to fully comprehend the potential advantages of Biodanza and SoE-verbal over a period of time.

\section{REFERENCES}

Adler, R. H., Herrmann, J. M., Koehle, K., Langewitz, W., Schonecke, O. W., Uexkuell, T., \& Wesiack, W. (Eds.). (2003). Psychosomatische Medizin [Psychosomatic medicine]. Munich: Urban \& Fischer Verlag.

Alexander, F. (1950). Psychosomatic medicine. Its principles and applications. New York: Norton Company.

Hofstede, G. (2007). Hofstede insights: What about Indonesia? Retrieved from www.hofstede-insights.com/ country/indonesia/ [accessed September 2, 2019].

Hofstede, G. (2011). Dimensionalizing cultures: The Hofstede model in context. Online Readings in Psychology and Culture, 2. https://doi.org/10.9707/23070919.1014

Ip, P. (2014). Harmony as happiness: Social harmony in two Chinese societies. Social Indicator Research, 117, 719-741. https://doi.org/10.1007/s11205-013-0395-7

López-Rodríguez, M. M., Baldrich-Rodríguez, I., RuizMuelle, A., Cortés-Rodríguez, A. E., Lopezosa-Estepa, T., \& Roman, P. (2017). Effects of Biodanza on stress, depression, and sleep quality in university students. Journal of Alternative and Complimentary Medicine, 23, 558-565. https://doi.org/10.1089/ acm.2016.0365

Magnis-Suseno, F. (2003). Etika Jawa: Sebuah analisa falsafi tentang kebijaksanaan hidup Jawa [Java ethics: Philosophy analysis about Javanese wisdom of life]. Jakarta: PT Gramedia

Mindell, A. (2002). The deep democracy of open forums: practical steps to conflict prevention and resolution for the family, workplace, and world. Charlottesville, VA: Hampton Roads Publishing Company.

Mueller, M., \& Poerschmann, N. (2009). Verbale Aspekte Wertschätzender Kommunikation im Kindergarten: Ein Handbuch auf der Basis der Gewaltfreien Kommunikation nach Marshall Rosenberg (Beiträge zur Bildungsgesundheit) [Verbal aspect of respectful communicatoon in Kidergarden: A handbook of the basic nonviolent communication from Marshall Rosenberg (A contribution for healthy education)]. Strassburg: Schibri Verlag.

Qudsyi, H., Trimulyaningsih, N., Novitasari, R., \& Stueck, M. (2018). Developing a module of nonviolent communication among children in $\mathrm{Yo}^{-}$ gyakarta. Proceeding of International Conference on Child-Friendly Education, Universitas Muhammadiyah Surakarta, April 21-22, 2018.

Rosenberg, M. (2007). Kinder einfühlend ins Leben begleiten: Elternschaft im Licht der gewaltfreien Kommunikation [Caring for children with empathy: Parenting in the light of non-violent communication]. Paderborn: Junfermann Verlag.

Rosenberg, M. (2015). Nonviolent communication: A language of life ( $3^{\text {rd }}$ ed.). Encinitas, CA: Puddle Dancer Press.

Schoppe, S., \& Stueck, M. (2012). Wertschätzende Kommunikation in Kindertagesstätten [Respectful communication in educational institution]. Praevention und Gesundheitsfoerderung, 7, 229-236. https://doi. org/10.1007/s11553-012-0352-3

Stueck, M. (2007). Neue Wege: Yoga und Biodanza in der Stressreduktion für Lehrers [New ways: Yoga and Biodanza in the stress reduction for teachers]. Strassburg: Schibri-Verlag.

Stueck, M. (2013). School of Empathy: Introduction and first results. In E. Witruk \& A. Wilcke (Eds.), Studies in educational and rehabilitation psychology, Vol. 4: Historical and cross-cultural aspects of psychology (pp. 497-510). Frankfurt am Main: Peter Lang.

Stueck, M., \& Villegas, A. (2008). Dance towards health? Empirical research to Biodanza - Biodanza mirrored in the science (Vol. 1). Strasburg: Schibri-Verlag.

Stueck, M., Villegas, A., Lahn, F., Bauer, K., Tofts, P., \& Sack, U. (2016). Biodanza for kindergarten children (TANZPRO-Biodanza): Reporting on changes of cortisol levels and emotion recognition. Body, Movement, and Dance in Psychotherapy, 11, 75-89. https://doi.org/10.1080/17432979.2015.1124923

Trimulyaningsih, N., Novitasari, R., \& Qudsyi, H. (2014). Nonviolent communication: An alternative approach for enhancing empathy among Indonesian children. Biopsychological Basics of Life, 1, 52-63.

Widiasmara, N., Novitasari, R., Trimulyaningsih, N., \& Stueck, M. (2018). School of Empathy for enhancing children's well-being. International Journal of Social Science and Humanity, 8, 230-234. https://doi.org/10.18178/ijssh.2018.V8.966 